\title{
Investigation of Hevea Brasiliensis Blends with an Aid of Rancimat Apparatus and FTIR Spectroscopy
}

\author{
Muhammad Irfan A A ${ }^{\# 1}$, Periyasamy $\mathrm{S}^{\# 2}$ \\ ${ }^{*}$ Department of Mechanical Engineering, \\ Government College of Technology, Coimbatore, Tamilnadu, India. \\ ${ }^{1}$ mechmuhammad@gmail.com \\ ${ }^{2}$ speriyasamy@gct.ac.in
}

\begin{abstract}
The lack of the fossil fuel, environmental pollution and food disaster are the world's major issues in current era. This research was carried out in commercial plant - rubber seed oil as a fuel. The production process of biodiesel comprises of two steps, esterification, and transesterification. The present work was investigating on the oxidation process of non-edible Hevea brasiliensis blends with an aid of Rancimat oxidation method. At different temperature the oxidation capacity of varies biodiesel blend was calculated. Form that the better oxidation biodiesel blend was identified. Properties like flash point, fire point and kinematic viscosity were assessed for representation of the samples. The fluid properties nearer to the diesel fuel were identified. Fourier Transformed Infrared Spectroscopy (FTIR) was used to recognize the functional groups of the samples. For the different ratio of biodiesel and diesel blends, the presence of alkenyl C-H Stretch, alkyl C-H Stretch, carboxylic acid C=O Stretch, C-H bend, and O-H bend were analyzed. The blends which confirm the alkyl $\mathrm{C}-\mathrm{H}$ Stretch, ester $\mathrm{C}=\mathrm{O}$ Stretch and $\mathrm{C}-\mathrm{H}$ bend are present with Decane structure. This result shows the possibility of improving the Hevea brasiliensis blends closer to diesel properties and may be vial for commercial usage.
\end{abstract}

Keyword- Hevea brasiliensis, Biodiesel, Oxidation stability, FTIR Spectroscopy.

NOMENCLATURE

CRSO - Crude Rubber Seed Oil

RSOME - Rubber Seed Oil Methyl Ester

B5 - Biodiesel 5\% + Diesel 95\%

B10 - Biodiesel 10\% + Diesel 90\%

B15 - Biodiesel 15\% + Diesel 85\%

B20 - Biodiesel 20\% + Diesel 80\%

FTIR - Fourier Transformed Infrared Spectroscopy

\section{INTRODUCTION}

Fossil fuel exhaustion and environmental anxiety have urged the need for a renewable alternate fuel which would be eco-friendly. Chand et al. [1] concluded biodiesels, alkyl esters of fatty acids resulting from glyceride sources, essentially natural products, and aid as promising alternatives because of its proper fuel properties and renewable nature. Marshed $\mathrm{M}$ et al. [2] claimed hevea brasiliensis being one of such fuel bases is rich in Asian countries, especially in Thailand, Indonesia, Malaysia and India. Atabani et al. [3] documented nature rubber was taken from the latex of rubber tree. Due to this, rubber tree is wildly cultivated in tropical places. Due to the growing demand for natural rubber with the growth of rubber industry, the cultivated area of rubber tree increases abnormally and this project to produce the biodiesel from these unused seeds. The dilution, transesterification, direct blending, thermal cracking (pyrolysis) supercritical and micro-emulsion, are used to produce the biodiesel fuel. Ahmad [4] and Serrano [5] identified that the high free fatty acid content of rubber oil has been reduced over a two-step acid esterification base transesterification process. This process is essential to improve fuel properties that develop the quality of biodiesel. Various constraints such as the speed anxiety, catalyst concentration, reaction temperature, methanol to oil molar ratio and reaction moment in time were achieved to get hold of the highest methyl ester yield of biodiesel production from these non-edible oils. 


\section{MATERIALS AND METHODS}

Methodology of this project work was explained in the following flow chart as shown in Figure 1.

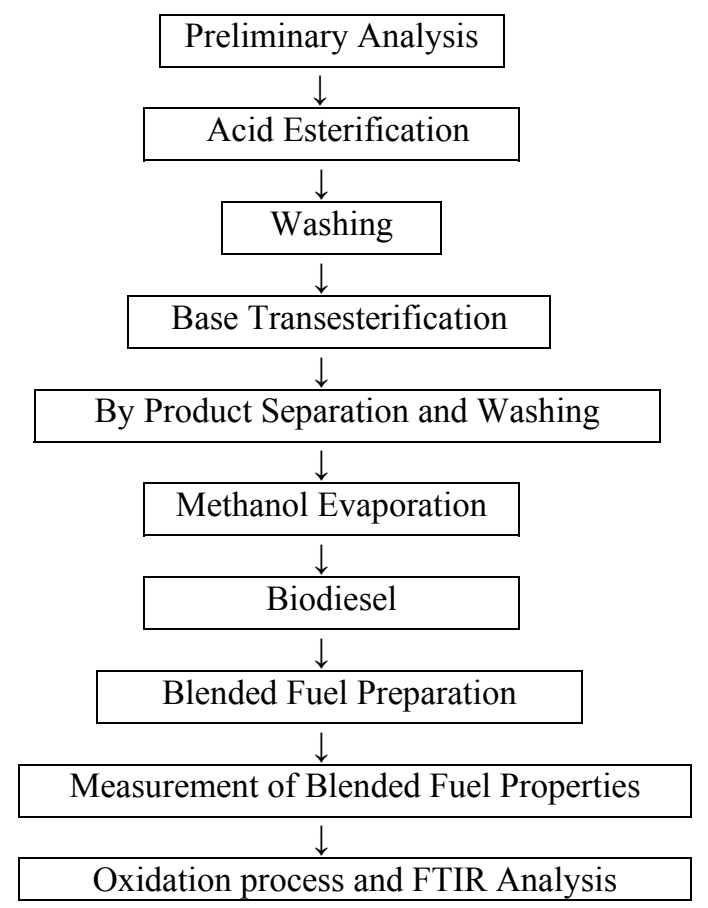

Fig. 1. Flow chart of biodiesel production and analysis of blended fuel

\section{A. Processing of Hevea Brasiliensis}

Half liter of Hevea brasiliensis oil was heated above $100^{\circ} \mathrm{C}$. After heating, the oil is cooled to $45^{\circ} \mathrm{C}-50^{\circ} \mathrm{C}$. Any dust or dirt particles present in it is removed, by filtering the cooled oil with a neat cloth. Acid esterification is to reduce the free fatty acids content in Hevea brasiliensis oil by esterification with 2:1 volume ratio of methanol and acid catalyst sulfuric acid in 90 minutes time at $57^{\circ} \mathrm{C}$ and $650 \mathrm{rpm}$ in a closed reactor vessel. After dewatering the esterified oil is fed to the transesterification process. Base transesterification done with 10:4 volume ratio of methanol and potassium hydroxide in 90 minutes time at $60^{\circ} \mathrm{C}$ and $650 \mathrm{rpm}$. The Hevea brasiliensis methyl ester was cleaned with distilled water to take away the entrained glycerin and impurities.

\section{III.RESULTS AND DISCUSSION}

As for finding the properties, oxidation stability and FTIR analysis on different proportion of the blended fuels were taken in to consideration.

\section{A. Kinematic viscosity of various fuel blends}

Figure 2 show that the kinematic viscosity is inversely proportional to the temperature for various fuel blends. Kinematic viscosity of biodiesel blend up to B5 is in same range equal to diesel. Kinematic viscosity increases at higher concentration of biodiesel blends above B5. Kinematic viscosity increases for RSOME when compared with other blends. Due to the higher viscosity of biodiesel than diesel, ones the blending concentration increases mean viscosity always increases. 


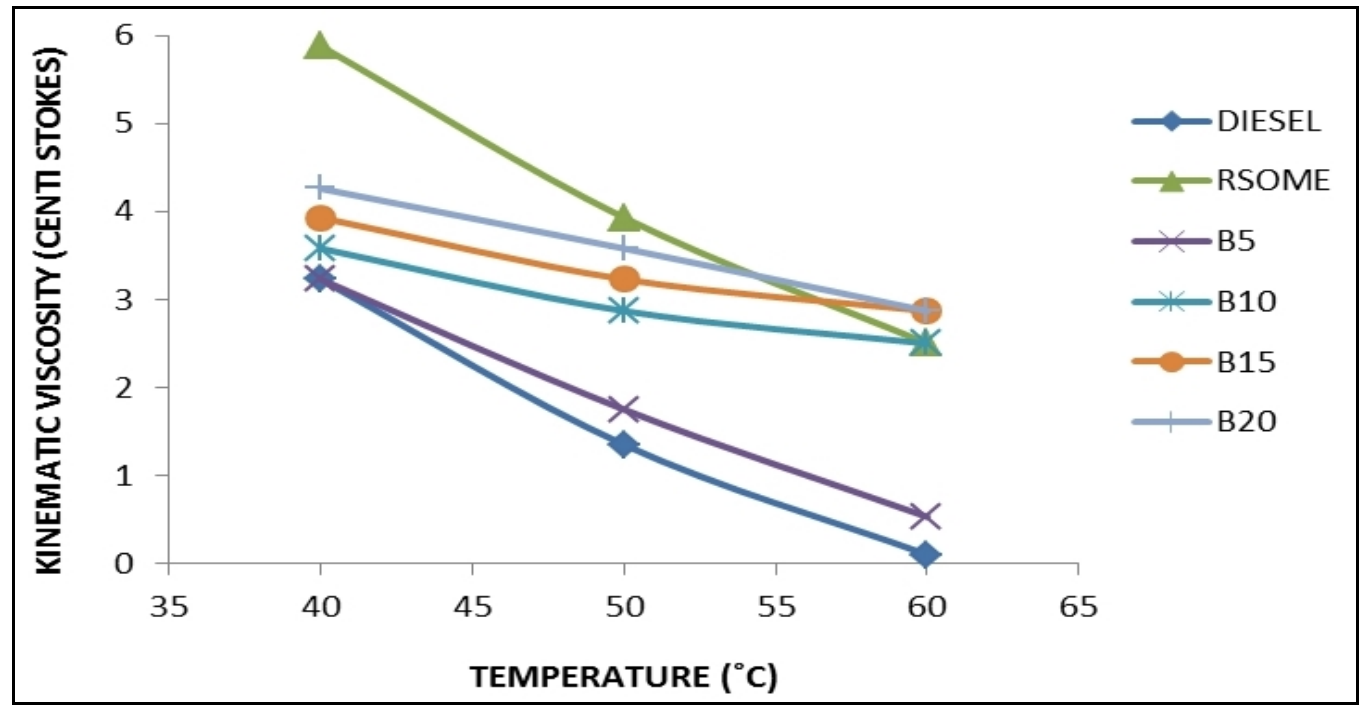

Fig. 2. Kinematic viscosity Vs Temperature

\section{B. Flash and Flash and Fire Points of Various Fuel Blends}

Figure 3 shows that the flash and fire point of the biodiesel blends are higher than diesel. Flash and fire point of biodiesel blend up to B5 are in same range equal to diesel.

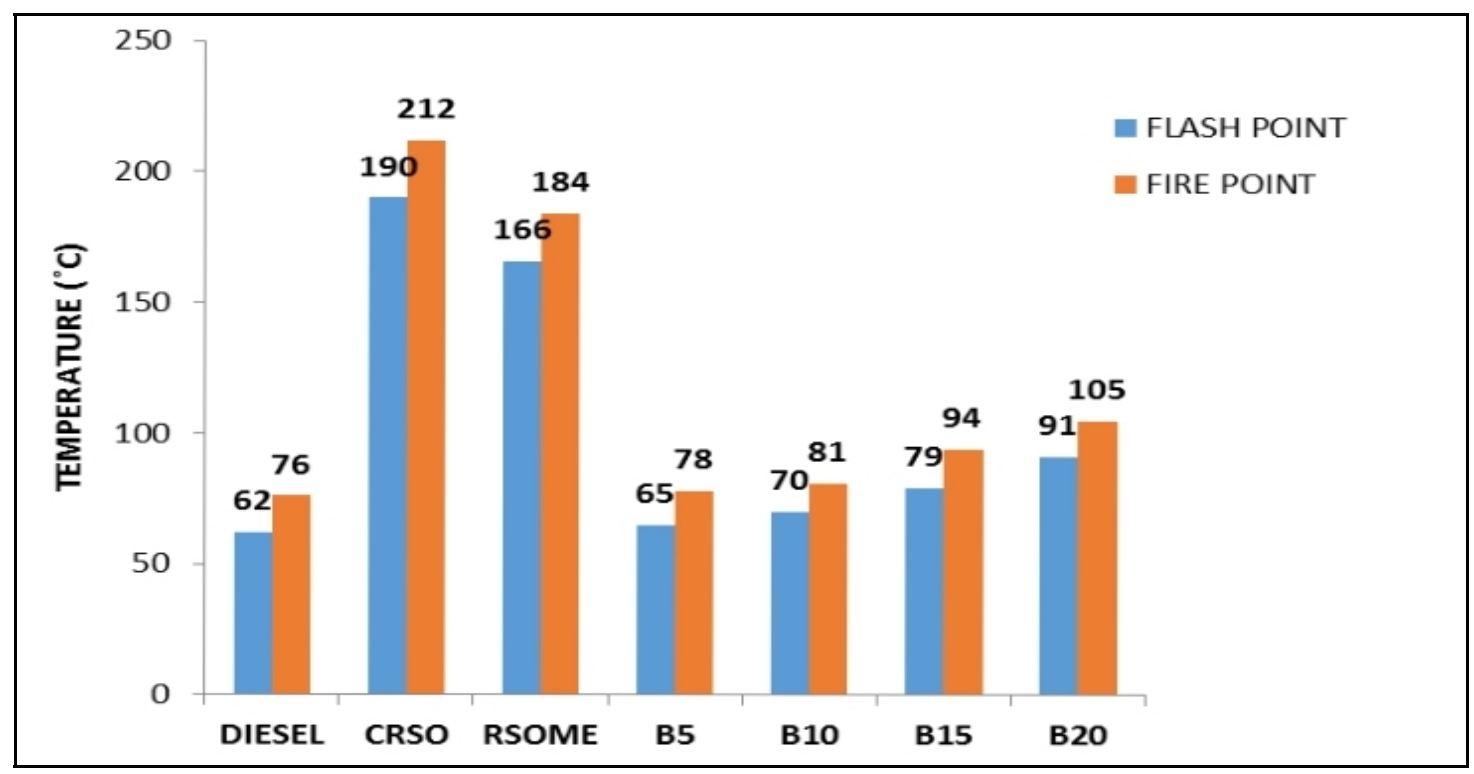

Fig. 3. Flash and fire point of various fuel blends

Flash and fire point increases at higher concentration of biodiesel blends above B5. Flash and fire point increases for CRSO when compared with other blends. Due to the higher flash and fire point of biodiesel than diesel, ones the blending concentration increases mean flash and fire point always increases.

\section{Determination of Oxidation Stability}

Figure 4 show that the shows that the oxidation stability decreases with increase in temperature. Oxidation stability of biodiesel blend up to $\mathrm{B} 20$ is in same range equal to diesel at $110^{\circ} \mathrm{C}$. Oxidation stability increases at higher concentration of biodiesel blends above B20. Oxidation stability increases for RSOME when compared with other blends. Due to the lower oxidation stability of biodiesel than diesel, ones the blending concentration increases mean oxidation stability always decreases. 


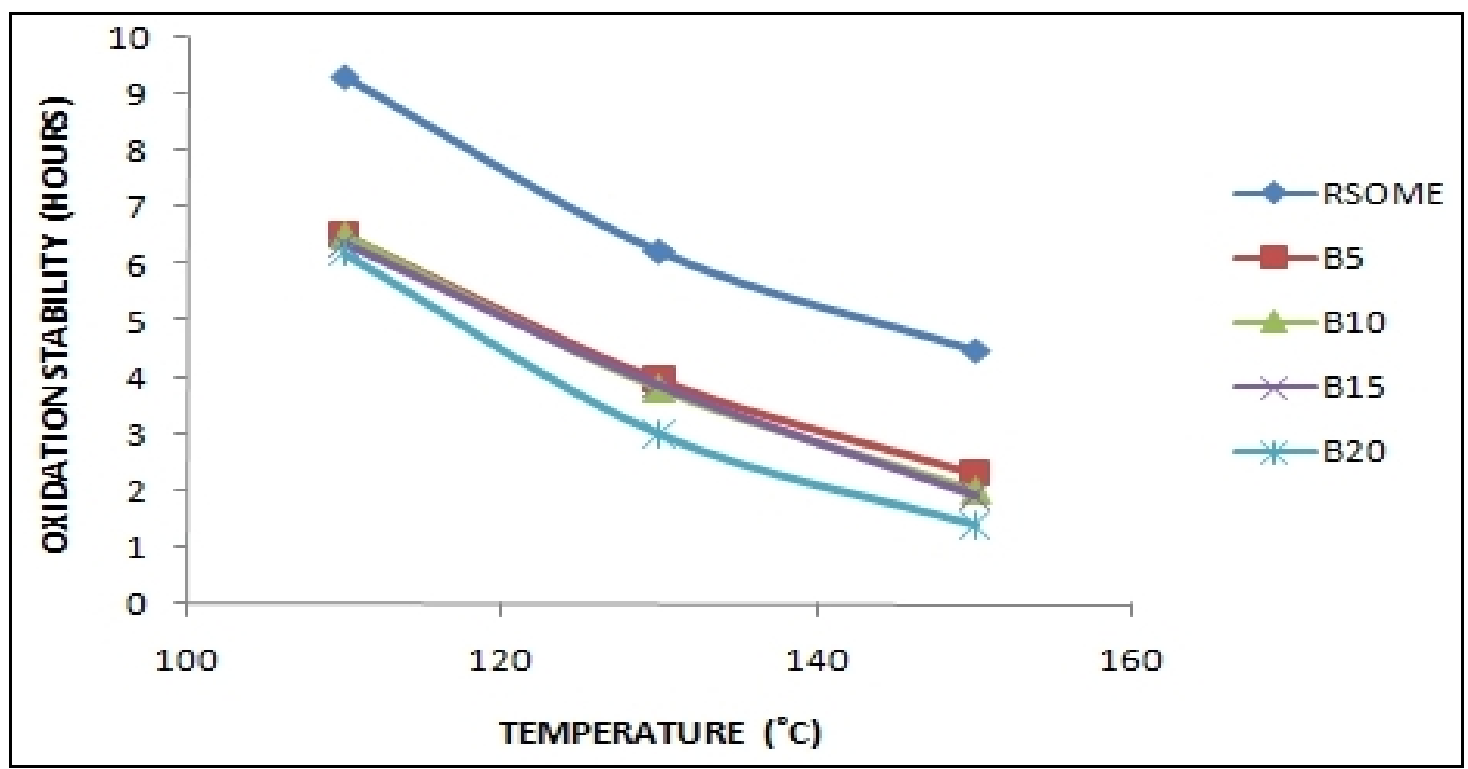

Fig. 4. Oxidation stability Vs Temperature

\section{FTIR Spectrum Analysis}

Upon first examination, a representative infrared spectrum can be visually divided into two sections. The left half, above $20001 / \mathrm{cm}$, usually comprises relatively few peaks, but some very analytic information can be found here. Normally contains many peaks in the right of the spectrum within the limit from $15001 / \mathrm{cm}$ to $8001 / \mathrm{cm}$. At varying intensities of these region which are not readily recognizable. This multipart lower region is also known as the fingerprint region because practically every organic compound produces a unique form in this area. Therefore character can often be confirmed by comparison of this region to a known spectrum. Figure 5 shows that the peak in the regions at $3008.731 / \mathrm{cm}, 2922.981 / \mathrm{cm}, 1711.671 / \mathrm{cm}, 1452.821 / \mathrm{cm}, 916.31 / \mathrm{cm}$ indicates the presence of alkenyl C-H Stretch, alkyl C-H Stretch, carboxylic acid C=O Stretch, C-H bend, O-H bend respectively. Figure 6 shows that the conversion of fatty acid to methyl esters. Peak in the region at 2923.41 $1 / \mathrm{cm}, 1749.421 / \mathrm{cm}$ and $1458.421 / \mathrm{cm}$ are indicates the presence of alkyl C-H Stretch, ester C=O Stretch and C$\mathrm{H}$ bend respectively. Best hit description is Decane with 0.842 score. Figure 7 shows that the peak in the region at $2922.961 / \mathrm{cm}$ and $1747.651 / \mathrm{cm}, 1457.881 / \mathrm{cm}$ are indicate the presence of alkyl C-H Stretch, ester $\mathrm{C}=\mathrm{O}$ Stretch and C-H bend respectively. Best hit description is Decane with 0.841 score.

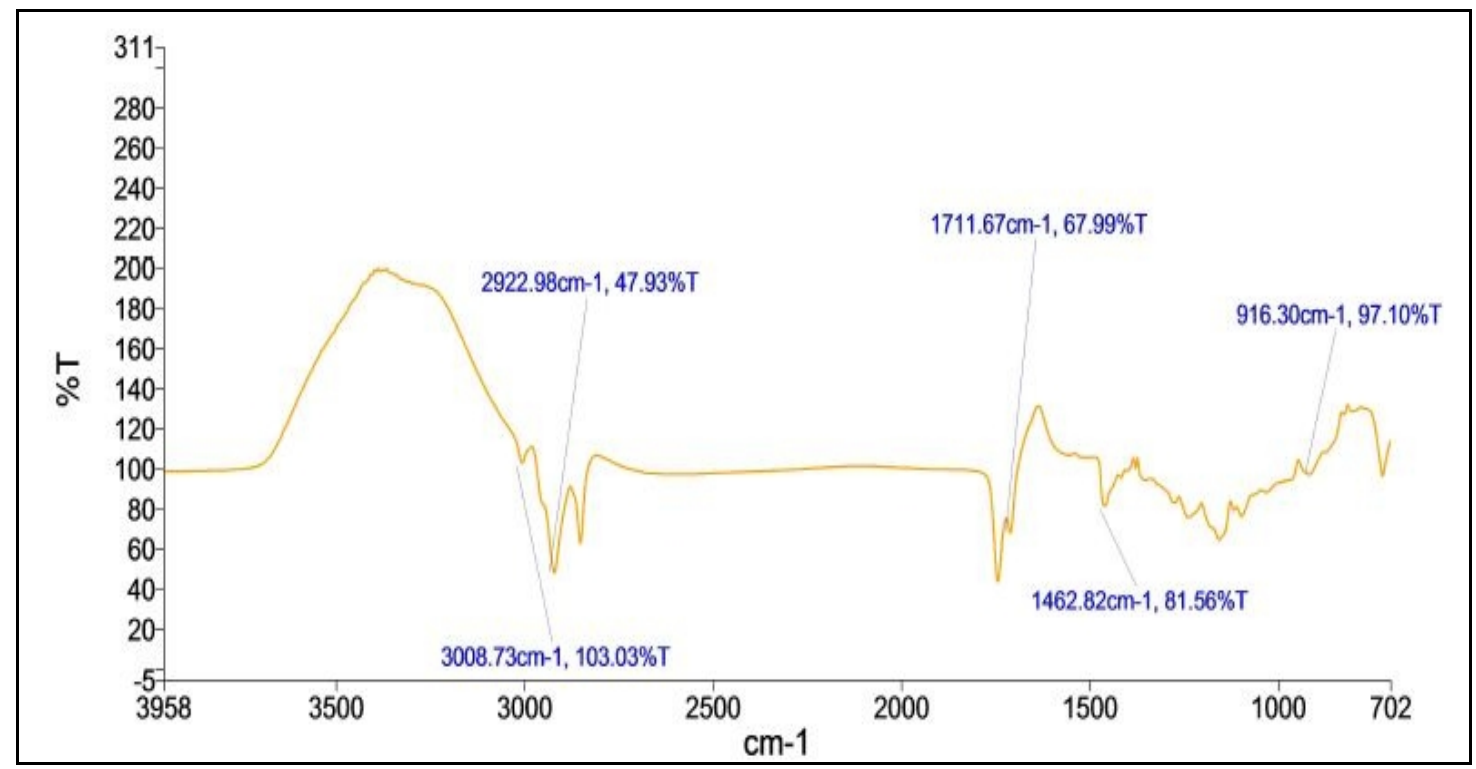

Fig. 5. FTIR spectrum for RSO 


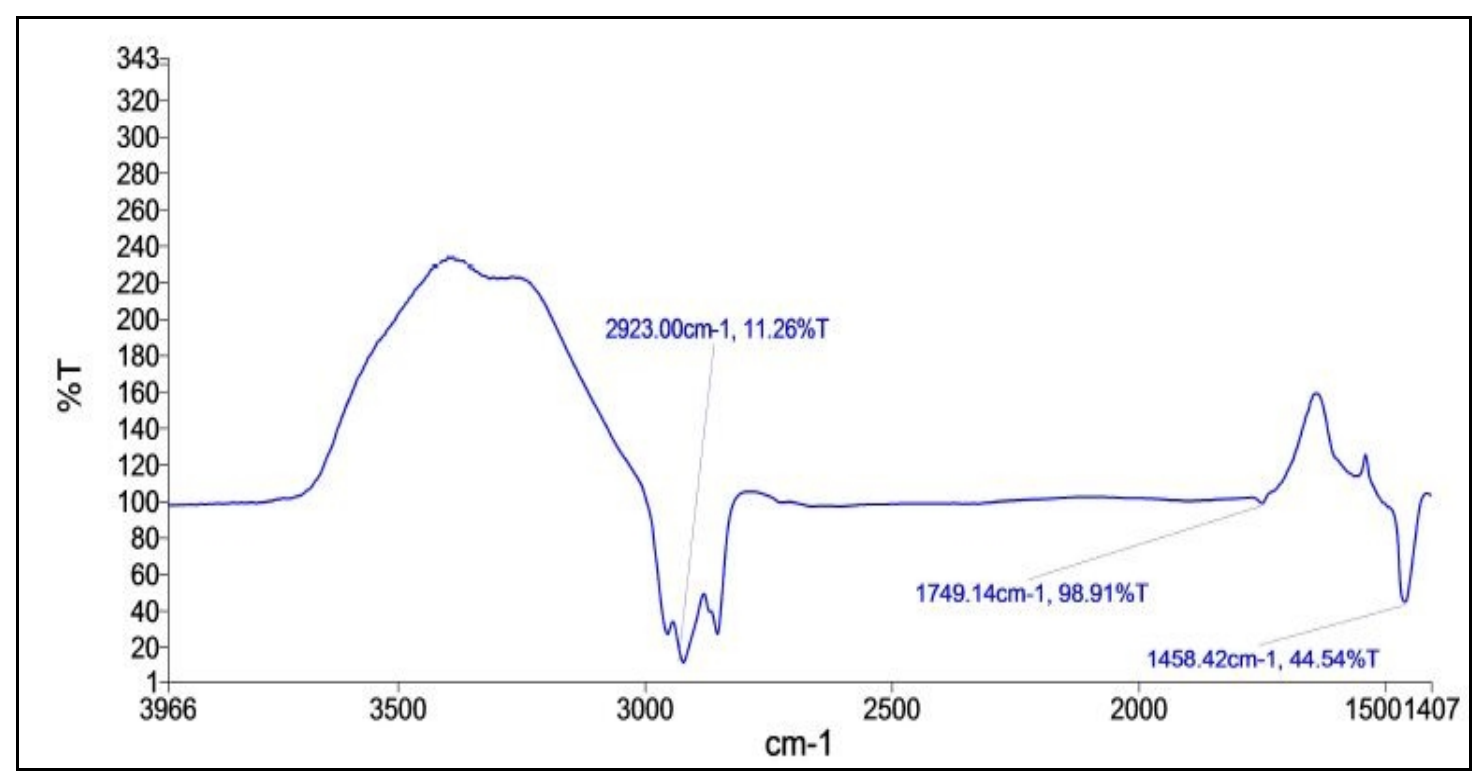

Fig. 6. FTIR spectrum for B10

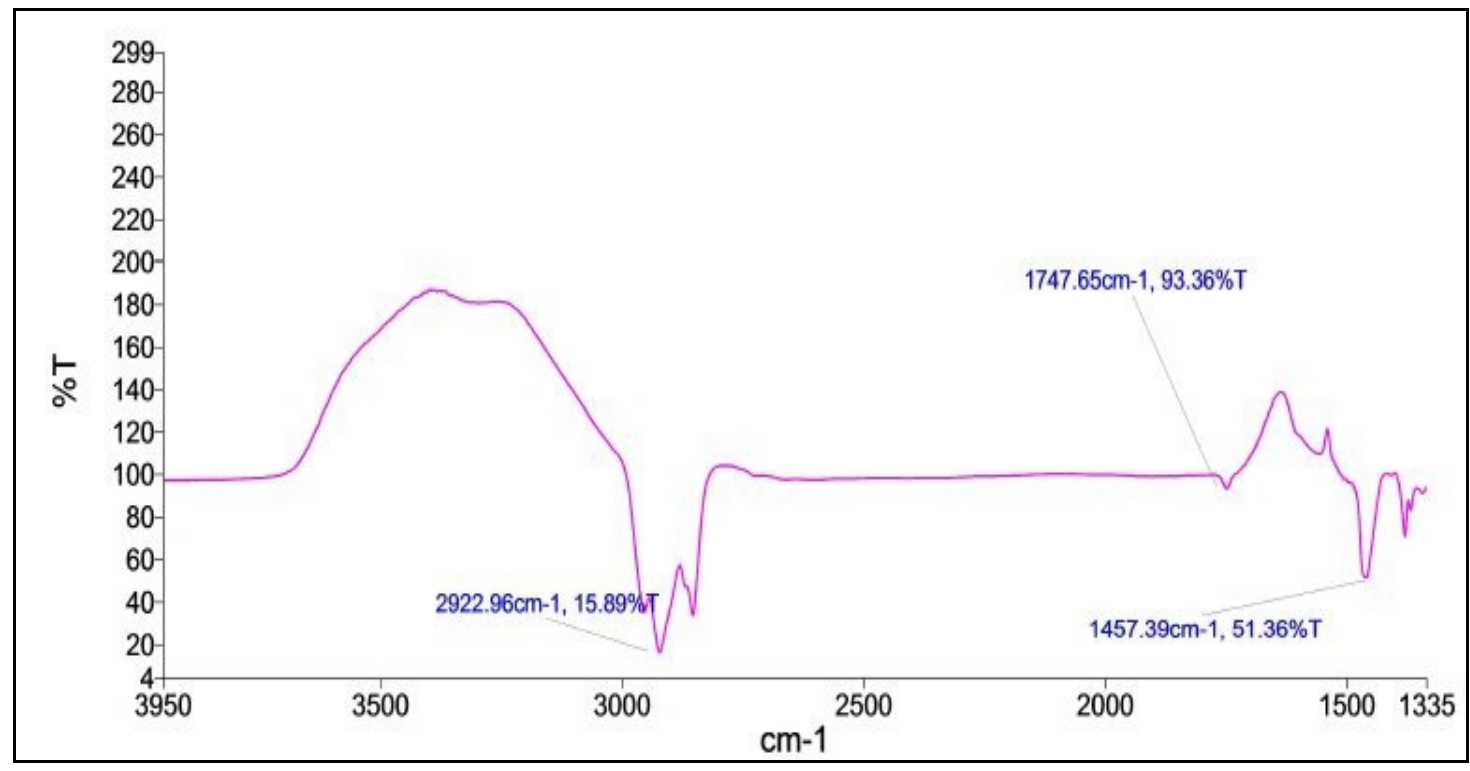

Fig. 6. FTIR spectrum for B15

\section{IV.CONCLUSION}

Hevea brasiliensis blends were successfully analyzed with an aid of Rancimat apparatus and FTIR spectroscopy. Percentage of increased in flash point and fire point are $206 \%$ and $178.95 \%$ respectively for biodiesel instead of diesel. At same time, it is increased to $4.84 \%$ and $2.63 \%$ for biodiesel blend B5 instead of diesel. Kinematic viscosity of biodiesel up to B5 is equal to diesel at $40^{\circ} \mathrm{C}$. Kinematic viscosity increases at higher concentration of biodiesel blends above B5. Oxidation stability of biodiesel up to B20 is almost in same range at $110^{\circ} \mathrm{C}$. Oxidation stability decreases $50.21 \%$ for RSOME when compared diesel. FTIR spectrum of biodiesel confirmed the conversion of fatty acid to methyl esters. All are the Hevea brasiliensis blends have alkyl C-H Stretch and Ester functional groups. FTIR spectrums of B10 and B15 are almost equal. These scores in decane structure are 0.842 and 0.841 respectively. 


\section{REFERENCES}

[1] Chand, P, Chintareddy V.R, Verkade J.G, Grewell D, "Enhancing biodiesel Production from Soybean oil using ultrasonics". Energy Fuels Vol. 24 (3), pp. 2010-2015, Feb. 2010. DOI: 10.1021/ef9011752

[2] Morshed M, Ferdous K, Khan M.R, Mazumder, M.S, Islam M.A, Uddin M.T, "Rubber seed oil as a potential source for biodiesel production in Bangladesh". Fuel Vol.90 (10), pp. 2981-2986, Oct. 2011. https://doi.org/10.1016/j.fuel.2011.05.020

[3] Atabani A.E, Silitonga A.S, Ong H.C, Mahlia T.M.I, Masjuki H.H, Badruddin I.A, Fayaz H, "Non-edible vegetable oils: a critical evaluation of oil extraction, fatty acid compositions, biodiesel production, characteristics, engine performance and emissions production”. Renew. Sustain. Energy Rev.vol.18, pp. 211-245, Feb. 2013. http://dx.doi.org/10.1016/j.rser.2012.10.013

[4] Ahmad J, Yusup S, Bokhari A, Kamil R.N.M, "Study of fuel properties of rubber seed oil based biodiesel". Energy Conversion Management Vol. 78, pp. 266-275, Feb. 2014. http://dx.doi.org/10.1016/j.enconman.2013.10.056

[5] Serrano M, Oliveros R, Sánchez M, Moraschini A, Martínez M, Aracil J, "Influence of blending vegetable oil methyl esters on biodiesel fuel properties: oxidative stability and cold flow properties. Energy Vol. 65, pp. 109-115, Feb. 2014. http://dx.doi.org/10.1016/j.energy.2013.11.072

\section{AUTHOR PROFILE}

Mr. Muhammad Irfan A A - B.E., Coimbatore Institute of Technology, Coimbatore (2013). M.E., Government College of Technology, Coimbatore (2017).

Dr. Periyasamy S - Assistant Professor, Government College of Technology, Coimbatore. - B.E., Thanthai Periyar Government Institute of Technology, Vellore. M.E., Madras Institute of Technology, Chennai. PhD., Anna University, Chennai. 